\title{
b-Gamma-glutamyltransferase activity in human vulnerable carotid plaques
}

\author{
Angela Pucci ${ }^{\text {a, }}{ }^{*}, 1$, Maria Franzini ${ }^{\text {b, }}{ }^{1}$, Marco Matteucci ${ }^{b}$, Sabrina Ceragioli ${ }^{\text {, }}$ \\ Michele Marconi ${ }^{c}$, Mauro Ferrari ${ }^{\text {c }}$, Claudio Passino ${ }^{\text {b, d, }}$, Fulvio Basolo ${ }^{\text {e, }}$ \\ Michele Emdin b, d, 1 , Aldo Paolicchi f, 1 \\ ${ }^{a}$ Histopathology Department, University Hospital, Pisa, Italy \\ ${ }^{\mathrm{b}}$ Institute of Life Sciences, Scuola Superiore Sant'Anna, Pisa, Italy \\ ${ }^{c}$ Vascular Surgery Department, University of Pisa, Italy \\ ${ }^{\mathrm{d}}$ Fondazione G. Monasterio CNR-Regione Toscana, Pisa, Italy \\ e Surgical and Medical Pathology Department, University of Pisa, Italy \\ ${ }^{\mathrm{f}}$ Translational Research Department, University of Pisa, Italy
}

\section{A R T I C L E I N F O}

\section{Article history:}

Received 28 May 2014

Received in revised form

2 September 2014

Accepted 19 September 2014

Available online 2 October 2014

\section{Keywords:}

Atherosclerosis

Gamma-glutamyltransferase fractions

Vulnerable plaque

\begin{abstract}
A B S T R A C T
Objective: The atherosclerotic plaque that is vulnerable to rupture and to superimposed thrombosis is mainly represented by a thin-cap fibroatheroma with or without ulceration/thrombosis and inflammatory infiltrates. Total serum gamma-glutamyltransferase (GGT) activity is an independent predictor for cardiovascular events. Four GGT fractions have been identified in plasma and only one of them (b-GGT) in atherosclerotic plaques, but the possible role of GGT in plaque pathophysiology has not been assessed yet. We investigated the relationships between plaque b-GGT activity and the histological features of plaque vulnerability. Methods and results: Plaque GGT activity was investigated in 65 patients undergoing carotid endarterectomy; plaques were histologically characterized and immunostained for GGT. Intra-plaque total and fractional GGT activity was determined by a cost-effective test of molecular size exclusion chromatography, and compared with histological markers of plaque vulnerability. Plaque cholesterol content was also measured by chromatography. b-GGT was the only fraction detected within the atherosclerotic plaques and intra-plaque b-GGT activity correlated to plaque cholesterol content $(r=0.667, P<0.0001)$, plasma b-GGT and f-GGT fractions $(r=0.249 ; r=0.298$, both $P<0.05)$. Higher bGGT activity was found in thin-cap fibroatheromas and it was associated to histological markers of vulnerable plaques, i.e., larger necrotic areas, greater macrophage infiltration and higher cholesterol content $(P<0.05)$. Conclusions: intra-plaque b-GGT activity correlates with the histological markers of vulnerable plaque and with plasma b-GGT in human carotid atherosclerosis; these data support the possible role of b-GGT in clinically significant atherosclerotic disease.
\end{abstract}

๑) 2014 Elsevier Ireland Ltd. All rights reserved.

\section{Introduction}

Cardiovascular diseases are leading causes of death, the social and economic burden of atherosclerosis increasing in the last decades together with population ageing [1]. Atherosclerosis is a progressive disease; cellular and molecular alterations within the arterial wall lead to lumen narrowing and/or to plaque rupture with

\footnotetext{
* Corresponding author. Histopathology Department, Pisa University Hospital, Via Roma, 57, 56125 Pisa, Italy.

E-mail addresses: a.pucci@ao-pisa.toscana.it, angelapucci@libero.it (A. Pucci).

${ }^{1} \mathrm{AP}, \mathrm{MFr}, \mathrm{ME}$, and APa equally contributed to this work.
}

superimposed acute thrombosis, such complicated plaques representing the antecedents for cardiovascular events [2-5].

The atherosclerotic plaques that are vulnerable to rupture and to thrombosis show well defined histological features [2,3,6-8]. Morbidity and mortality from atherosclerosis is largely due to vulnerable plaques, i.e., type IV-VI lesions according to the American Heart Association (AHA) classification, corresponding to thincap fibroatheromas with or without ulceration/fissuration showing a large necrotic core and abundant inflammatory infiltrates, mainly constituted by macrophages [9-11]. Conversely, stable lesions usually correspond to predominantly fibrous/fibrocalcific plaques and to thick-cap fibroatheromas with low or absent inflammation, 
absent or small necrotic core, no ulceration/fissuration or thrombosis [8-12].

The evolution of the atherosclerotic plaque towards stabilization or vulnerability is not completely understood so far [13], the search for in vivo biomarkers of plaque instability and subsequent lifethreatening complications representing a major challenge of modern medicine [14-18].

During the last decade, total serum gamma-glutamyltransferase (GGT) activity has been recognized as a risk factor for both coronary and cerebrovascular events in unselected populations $[19,20]$ as well as in patients with diagnosed coronary artery disease [21]. Its predictive value is independent and additive, as compared to other established markers, and independent from liver disease or alcohol consumption $[17,19,21]$.

As to the possible role of GGT in plaque instability, its active form has been previously shown to co-localize with inflammatory cell infiltrates and peroxidized low-density lipoprotein (LDL) in both coronary and carotid plaques [16,21,22]. The GGT activity has been hypothesized to exert a direct pro-oxidant activity, eliciting the production of reactive oxygen species from cystenylglycine (CysGly) moieties via its catalytic activity on extracellular glutathione [23-25], the occurrence of GGT-mediated redox reactions having been demonstrated within the plaque [26]. Recently, four plasma GGT fractions have been identified by molecular size exclusion chromatography, i.e., b-GGT, m-GGT and s-GGT (that very likely represent $>2000,940$ and $140 \mathrm{kDa}$, respectively, lipoproteinbound molecular masses) plus the $70 \mathrm{kDa}$ free fraction f-GGT $[27,28]$; only the highest molecular weight fraction b-GGT, has been found within atherosclerotic plaques by our group [26].

The aim of this study is to evaluate the possible relationships between intra-plaque b-GGT content, localization and activity and the histological features of plaque vulnerability in carotid atherosclerosis; in order to better understand the pathophysiology of high-risk plaque formation. Plasma GGT fractions are also investigated in the same patients.

\section{Materials and methods}

\subsection{Study population}

We investigated 65 consecutive patients undergoing carotid endarterectomy at the General and Vascular Surgery (University Hospital, Pisa, Italy). Since endarterectomy is recommended in patients with severe carotid artery stenosis ( $>70 \%)$, even in absence of neurological symptoms, the major part of this cohort was constituted by asymptomatic patients $(n=50)$, while 15 patients showed neurological symptoms. The indication for endarterectomy was based on the recommendations published by the Asymptomatic Carotid Surgery Trail and on the European Carotid Surgery Trail and the North American Symptomatic Carotid Endarterectomy Trail [29-32].

In all cases, baseline data were obtained by clinical files, including history of vascular disease, cardiovascular risk factors and medication use. Patients were on appropriate therapy with lipidand/or glucose-lowering drugs, anti-coagulant or antiplatelet agents, anti-hypertensive drugs, according to current guidelines. Carotid stenosis severity was evaluated by ultrasound analysis. Hypertension was defined as systolic blood pressure $\geq 140 \mathrm{mmHg}$ and/or a diastolic pressure $\geq 90 \mathrm{mmHg}$, with or without antihypertensive treatment at the time of endarterectomy. Diabetes mellitus was diagnosed in patients with fasting blood glucose $>126 \mathrm{mg} / \mathrm{dL}$, and/or current oral or insulin treatment. Dyslipidemia was diagnosed as total cholesterol level $>200 \mathrm{mg} / \mathrm{dL}$ ( $>5.18 \mathrm{mmol} /$ L) and/or serum triglycerides $\geq 150 \mathrm{mg} / \mathrm{dL}$ ( $>1.70 \mathrm{mmol} / \mathrm{L})$, and/or current statin/fibrate treatment.
The study was approved by the Institutional Ethics Committee, and conformed to the Declaration of Helsinki, and patients gave the informed consent.

Standard assay of all blood tests were simultaneously performed according to the standard clinical laboratory procedures by automated analysers, plasma high sensitivity C-reactive protein (hsCRP) was determined on Synchron CX instrument (Beckman, USA).

\subsection{Tissue sampling}

Surgically excised carotid plaques were collected on ice and dissected into 5-mm segments. Adjacent segments having the greatest plaque area and representing the culprit lesion, were fixed in $10 \%$ buffered formalin or in $70 \%$ cold ethanol and paraffinembedded for histological analyses, and frozen at $-20{ }^{\circ} \mathrm{C}$ after being rinsed in cold Dulbecco's phosphate buffer for biochemical investigations, respectively. In a sub-group of these patients $(N=20)$ with adequate plaque volume, a third segment of the plaque was frozen at $-20^{\circ} \mathrm{C}$ in Optimal Cutting Temperature (OCT) medium.

Plaque fragmentation due to the surgical procedure was minimal, allowing histological analysis in all cases.

\subsection{Histopathological investigations}

Serial $3 \mu \mathrm{m}$ paraffin sections were stained with haematoxylineosin and Masson's trichrome method. Immunohistochemistry was performed on adjacent paraffin-embedded sections. Macrophages were identified by immunoperoxidase staining by using a specific monoclonal antibody raised against CD68 antigen, and endothelial cells by the antibody against CD31 antigen (Dakopatts, Glostrup, Denmark); immunoreactions were visualized by 3diaminobenzidine substrate. GGT immunostaining was performed by using a previously characterized polyclonal antibody directed against the heavy chain of human GGT antigen at the appropriate dilution $(1: 1600)$ [33].

GGT enzymatic activity was evaluated both on $5 \mu \mathrm{m}$ OCT embedded cryostat sections and on serial $3 \mu \mathrm{m}$ paraffin sections obtained from plaques fixed in ethanol. The histochemical reaction was performed by using the specific substrate gamma-glutamyl-4methoxy-2-naphtylamide and the diazonium salt Fast Blue BB as a chromogen [34].

The tissue areas constituted by lipidic core, fibrous tissue, calcification or immunostained for CD68 were automatically measured by a grey scale detection method with a fixed threshold by a computer-based morphometry software (J-Image, NIH, Bethesda, Maryland; USA).

\subsection{Histological characterization of plaques}

The plaques were histologically classified according to the American Heart Association (AHA) scheme [2,3] and, for the aim of the study, were categorized as stable or vulnerable plaques [7,9]. The vulnerable plaques were defined by the presence of a thin cap fibroatheroma, i.e., a fibrous cap $<165 \mu \mathrm{m}$ thick, whereas the stable plaques corresponded to predominantly fibrous lesions with a fibrous cap $\geq 165 \mu \mathrm{m}$ thick.

To investigate possible relationships between plaque histology and intra-plaque b-GGT, the plaque components were categorized according to the following scoring system: a) necrotic core, score 0 (absent), 1 (low, i.e., representing up to $25 \%$ of the total plaque area), 2 (medium, $>25-50 \%$ ) or 3 (high, $>50 \%$ ); b) fibrous tissue, score 1 (low, up to $30 \%$ ), 2 (medium, $>30-60 \%$ ) or 3 (high, $>60 \%$ ); c) calcifications, score 0 (absent), 1 (low, up to 15\%), 2 (medium, 
$>15-30 \%$ ) or 3 (high, $>30 \%$ ); d) macrophage infiltration, score 0 (absent), 1 (low, up to $5 \%$ ), 2 (medium, $>5-10 \%$ ) or 3 (high, $>10 \%$ ).

\subsection{Homogenates of atherosclerotic lesions}

Portions of plaque were snap-frozen in liquid nitrogen, mechanically disrupted and homogenized in 5\% volume of cold hypotonic buffer (PBS diluted 10 folds) using a Potter homogenizer. Crude homogenates were centrifuged at $1000 \mathrm{~g}, 5 \mathrm{~min}, 4^{\circ} \mathrm{C}$ and the supernatant was further centrifuged $10,000 \mathrm{~g}, 15 \mathrm{~min}, 4^{\circ} \mathrm{C}$, the final sample was then used for fractional GGT analysis.

\subsection{Fractional GGT analysis}

Fractional GGT analysis was performed as previously described $[27,28]$ using an FPLC (fast protein liquid chromatography) system (AKTA purifier, GE Healthcare Europe, Milan, Italy) equipped with a gel-filtration column (Superose 6 HR 10/300 GL, GE Healthcare Europe) and a fluorescence detector (Jasco FP- 2020, Jasco Europe, Lecco, Italy). Plaque homogenates and plasma samples $(0.02 \mathrm{ml})$ were injected in the gel-filtration column, after being filtered with a $0.45 \mu \mathrm{m}$ polyvinylidene fluoride Millipore filter. GGT activity was measured using gamma-glutamyl-7-amido-4-methylcoumarin (Nova Chimica, Milan, Italy) as substrate $(0.03 \mathrm{mmol} / \mathrm{L}$, final concentration) and glycylglycine (5.4 mmol/L, final concentration) as acceptor of the transpeptidation reaction. The fluorescence detector operating at excitation/emission wavelengths of 380/440 nm detected the amino-4-methylcoumarin signal; the intensity of the fluorescence signal was expressed in arbitrary fluorescence units.

Under this reaction conditions, area under curve is proportional to GGT activity. Total area, between 10 and $25 \mathrm{~mL}$ elution volume, and fractional GGT area was calculated by a MatLab program (Version 7 MathWorks, Inc.) to resolve overlapping peaks; the curve fitting was conducted with a nonlinear least-squares minimization algorithm using four exponentially modified Gaussian (EMG) curves. The reaction was calibrated analysing plasma samples with known total GGT activity (standards). The slope of the calibration curve was used to convert total and fractional GGT area to $U / L$. The sum of fractional GGT activity represents on average the $99 \%$ of total GGT activity. A $4.5 \mathrm{mmol} / \mathrm{L}$ stock solution of gammaglutamyl-7-amido-4-methylcoumarin was prepared in ethanol $40 \%$ $\mathrm{v} / \mathrm{v}$ containing $0.01 \mathrm{~N} \mathrm{NaOH}$ and stored at $-20^{\circ} \mathrm{C}$. This solution was diluted 25 -fold into $0.25 \mathrm{M}$ Tris- $\mathrm{HCl}$ buffer $\mathrm{pH} 8.5\left(25^{\circ} \mathrm{C}\right)$ daily.

\subsection{Cholesterol analysis by high-performance gel filtration chromatography}

Distribution profile of the cholesterol in plaque homogenates was obtained by the fractional GGT analysis method, but a commercially available reagent for total cholesterol determination (GiesseDiagnostic, Rome, Italy) was used as post-injected reagent. Reaction product was detected by recording the absorbance at $510 \mathrm{~nm}$.

\subsection{Statistical analysis}

Continuous variables are expressed as mean \pm standard deviation (SD), or median (25th-75th percentile), as appropriate. Variables with known skewed distributions were natural logarithmically transformed before further analysis. Statistical analysis of data was performed by Student's $t$-test and Pearson's correlation analysis. A $P$ value $<0.05$ was considered to indicate significance.

\section{Results}

\subsection{Population characteristics}

Study patients were elderly (age $73.5 \pm 8.1$ years, 46 males) and showed, as expected, a high prevalence of arterial hypertension (86\%) and/or dyslipidemia (85\%) with overweight in 43\% patients, diabetes in $39 \%$, concomitant ischaemic heart disease in $29 \%$, current smoking habit in $22 \%$. Detailed clinical and biohumoral characteristics of the study population, including values related with analysis of total and fractional plasma GGT activity are reported in Table 1.

\subsection{Intra-plaque GGT and correlations with plasma GGT fractions}

Plaque homogenates displayed GGT activity in all but one case, corresponding to an exclusively fibrous plaque without necrotic core.

Total GGT activity of plaque homogenates ranged between 7.6 and $126.4 \mathrm{mU} / \mathrm{g}$ tissue $(43.8 \pm 27.3)$. A unique distinct peak of bGGT was identified at fractional GGT analysis (Fig. 1), with a mean activity of $15.4 \pm 10.7 \mathrm{mU} / \mathrm{g}$ tissue (range $2.6-46.7 \mathrm{mU} / \mathrm{g}$ tissue).

Intra-plaque b-GGT activity was shown to correlate with intraplaque total cholesterol content, as well as with plasma b- and fGGT fractions, and fibrinogen (Table 2). No correlation was found between intra-plaque b-GGT and serum triglyceride, fasting glucose, leucocytes or hs-CRP (Table 2). No association was found between intra-plaque b-GGT levels and the extent of lumen narrowing at echo-Doppler examination (stenosis $<80 \%$, $13.8 \pm 9.3 \mathrm{mU} / \mathrm{g}$ tissue; stenosis $\geq 80 \%: 15.8 \pm 10.8 \mathrm{mU} / \mathrm{g}$ tissue; $P=0.4987)$.

A residual GGT activity within the plaques, without discrete peaks (Fig. 1), was detected $(28.4 \pm 17.6 \mathrm{mU} / \mathrm{g}$ tissue, range

Table 1

Patients' characteristics.

\begin{tabular}{lc} 
& \\
\hline Age, $\mathrm{y}$ & Subjects $(n=65)$ \\
Males, $n$ (\%) & $74(68-79)$ \\
BMI, kg/m ${ }^{2}$ & $46(70.8)$ \\
Diabetes, $n$ (\%) & $26.8(24.4-27.8)$ \\
Hypertension, $n(\%)$ & $25(38.5)$ \\
Dyslipidemia, $n(\%)$ & $56(86.2)$ \\
Cerebrovascular symptoms, $n$ (\%) & $55(84.6)$ \\
Ischaemic heart disease, $n$ (\%) & $15(23.1)$ \\
Glucose, mg/dL & $19(29.2)$ \\
Creatinine, mg/dL & $107(98-121)$ \\
Albumine, g/dL & $1.1(0.9-1.3)$ \\
Bilirubin, mg/dL & $4.4(4.2-4.6)$ \\
Cholesterol, mg/dL & $0.4(0.3-0.5)$ \\
HDL, mg/dL & $191(166-213)$ \\
LDL, mg/dL & $45(43-55)$ \\
Triglycerides, mg/dL & $113(100-132)$ \\
AST, U/L & $125(99-172)$ \\
ALT, U/L & $20(16-25)$ \\
ALP, U/L & $19(13-26)$ \\
Leucocytes, $10^{3} / \mathrm{mL}$ & $79(64-100)$ \\
Fibrinogen, mg/dL & $7.4(6.5-8.6)$ \\
hs-CRP, mg/dL & $396(366-432)$ \\
Total GGT, U/L & $0.3(0.1-0.6)$ \\
b-GGT, U/L & $24.97(19.06-38.77)$ \\
m-GGT, U/L & $2.84(1.80-5.79)$ \\
s-GGT, U/L & $0.74(0.40-1.24)$ \\
f-GGT, U/L & $9.20(5.26-16.82)$ \\
& $13.21(10.09-15.02)$ \\
\hline
\end{tabular}

Data are reported as median (25th-75th percentiles). BMI, body mass index; HDL, high density lipoprotein, LDL low density lipoprotein; AST, aspartate aminotransferase; ALT, alanine aminotransferase; ALP, alkaline phosphatase; GGT, gammaglutamyltransferase; hs-CRP, high sensitivity C-reactive protein. 


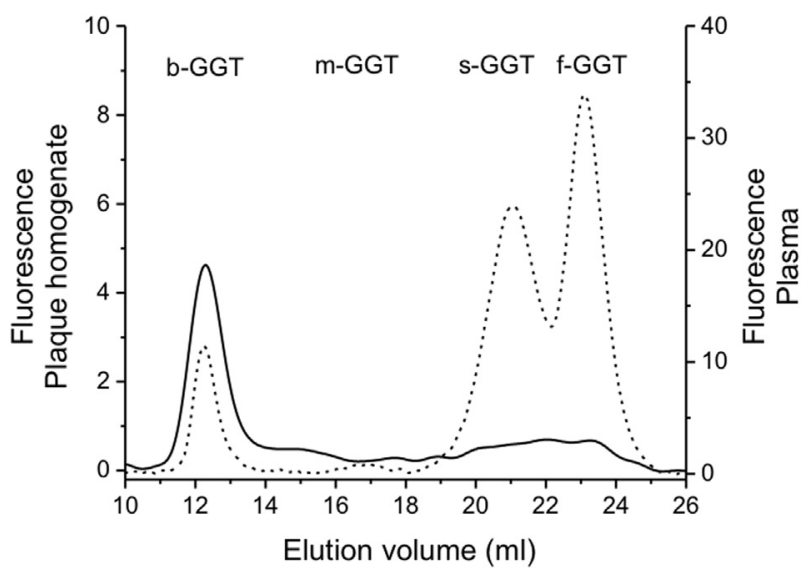

Fig. 1. Representative elution profile of GGT activity in plaque homogenate (continuous line) and plasma (dashed line) obtained from the same patient (C28). Elution profile was obtained by molecular exclusion chromatography, and GGT activity was detected by an on-line post-column reaction in presence of a fluorescent substrate, $\gamma$ GluAMC [28].

4.1-79.7 $\mathrm{mU} / \mathrm{g}$ tissue). It showed a significant correlation with intra-plaque cholesterol and plasma f-GGT fraction only (Table 2).

\subsection{Plaque histology and GGT}

The total mean area of the examined endarterectomy specimens was $65.67 \pm 8.27 \mathrm{~mm}^{2}$. According to the AHA histological classification of atherosclerosis [2,3], 20 (32\%), 10 (15\%), and 1 plaques were defined as type $\mathrm{Va}, \mathrm{Vb}$, and $\mathrm{Vc}$, respectively, whereas $12(18 \%)$, $14,(22 \%), 3,(5 \%)$ and 5 ( $8 \%$ ) were categorized as type VIa, VIb, VIc and VIabc, respectively. No type I-IV plaque was found.

A detailed histopathological characterization of vulnerability features is reported in Supplemental data Table 1. Thirty-four out of 41 vulnerable plaques (87\%) were type VI according to AHA classification, 7 (13\%) were type $\mathrm{V}$, while all 24 stable plaques (100\%) were type $\mathrm{V}$ lesions.

As expected, thin-cap fibroatheromas ( $n=41,63 \%$ ) were characterized by large necrotic core and high macrophage infiltration (Fig. 2, panels A-C), whereas stable plaques ( $n=24,37 \%)$ showed a thick-cap fibroatheroma, small necrotic cores and light macrophage infiltration (Fig. 2, panels D-F) in all but one case with exclusively fibrous content and no necrotic core.

Table 2

Bivariate correlation analysis between intra-plaque b-GGT and residual GGT activity (mU/mg tissue), intra-plaque cholesterol content ( $\mathrm{mg} / \mathrm{g}$ tissue) and plasma analytes.

\begin{tabular}{|c|c|c|c|c|}
\hline & \multicolumn{2}{|c|}{ Intra-plaque b-GGT } & \multicolumn{2}{|c|}{$\begin{array}{l}\text { Intra-plaque } \\
\text { residual GGT }\end{array}$} \\
\hline & $r$ & $P$ & $r$ & $P$ \\
\hline Intra-plaque cholesterol & 0.667 & $<0.0001$ & 0.469 & 0.0003 \\
\hline hs-CRP & -0.084 & 0.5143 & -0.018 & 0.8875 \\
\hline Fibrinogen & -0.281 & 0.0320 & -0.327 & 0.0124 \\
\hline Leucocytes & 0.080 & 0.5484 & 0.073 & 0.5840 \\
\hline Fasting glucose & 0.058 & 0.6591 & -0.025 & 0.8468 \\
\hline Triglycerides & 0.027 & 0.8454 & 0.080 & 0.5649 \\
\hline Total GGT & 0.242 & 0.0582 & 0.241 & 0.0553 \\
\hline b-GGT & 0.249 & 0.0470 & 0.206 & 0.1033 \\
\hline m-GGT & 0.203 & 0.1152 & 0.187 & 0.1390 \\
\hline s-GGT & 0.169 & 0.1939 & 0.180 & 0.1543 \\
\hline f-GGT & 0.298 & 0.0170 & 0.341 & 0.0058 \\
\hline
\end{tabular}

Data are reported as Pearson correlation coefficients. hs-CRP, high sensitivity Creactive protein; GGT, gamma-glutamyltransferase. Intra-plaque residual GGT activity was calculated as the difference between intra-plaque total GGT and b-GGT activity.
Immunohistochemical (Fig. 2) and histoenzymatic staining showed the presence of variable amounts of immunoreactive and catalytically active GGT, mainly localized to plaque areas corresponding to necrotic core, foamy macrophage-rich sites, and, to a lesser extent, to the endothelial lumen layer and/or to intra-plaque neoangiogenetic vessels (Supplemental Figs. 1 and 2).

As compared to thick-cap plaques, thin-cap fibroatheromas showed significantly higher $(P<0.05)$ intra-plaque GGT activity, both as b-GGT ( $16.8 \pm 10.0$ vs. $13.0 \pm 11.7 \mathrm{mU} / \mathrm{g}$ tissue, Fig. 3$)$ and residual GGT activity $(31.4 \pm 17.0$ vs. $23.1 \pm 17.8 \mathrm{mU} / \mathrm{g}$ tissue, Supplemental data Fig. 3) and higher cholesterol content $(0.24 \pm 0.21$ vs. $0.13 \pm 0.08 \mathrm{mg} / \mathrm{g}$ tissue, $P<0.05)$. As to the other histological features (Fig. 3), plaques with larger necrotic cores (score 3 ) showed a higher intra-plaque b-GGT activity as compared to those with small/medium necrotic core (scores $0-2 ; 17.2 \pm 16.2$ vs. $12.3 \pm 10.4 \mathrm{mU} / \mathrm{g}$ tissue, $P<0.036$ ). Plaque b-GGT activity was also higher in presence of a high $v s$. low macrophage infiltration (score $2-3$ vs. score $0-1 ; 16.7 \pm 11.0$ vs. $11.1 \pm 8.8 \mathrm{mU} / \mathrm{g}$ tissue, $P<0.025)$. Either fibrous component and calcium content were negatively associated with intra-plaque b-GGT activity, the lowest fibrous tissue score 1 corresponding to higher b-GGT activity as compared to higher fibrous scores $(2-3 ; 16.8 \pm 10.3$ vs. $11.7 \pm 11.3 \mathrm{mU} / \mathrm{g}$ tissue, $P<0.023$ ), and the highest calcium content (scores 2-3) showing lower levels of b-GGT as compared to scores $0-1(10.5 \pm 10.4$ vs. $17.4 \pm 10.3 \mathrm{mU} / \mathrm{g}$ tissue, $P<0.01)$.

As to intra-plaque residual GGT activity, significant lower levels were found only in plaques with higher calcium content $(21.9 \pm 17.2$ vs. $30.9 \pm 17.3 \mathrm{mU} / \mathrm{g}$ tissue, $P<0.05$ ), whereas no association was found with necrotic core, macrophage infiltration and fibrous component (Supplemental Fig. 3). Finally, no correlation was found between all above mentioned plaque histological features and hsCRP circulating levels.

Plasma total and fractional GGT activity showed no statistically significant relationship with histological plaque features of instability (data not shown).

\section{Discussion}

This is the first study demonstrating that a specifically higher extent and activity of intra-plaque b-GGT is characteristic of plaques with the histological features of vulnerability, i.e., thin-cap fibroatheromas with large necrotic core and high macrophage infiltration $[7,9]$ that have been previously shown to be associated with adverse clinical events on either in vivo (i.e., on carotid endarterectomies) and post-mortem studies [6,7,9]. Accordingly to the AHA histological classification of atherosclerosis, most vulnerable plaques $(87 \%)$ of the present study corresponded to type VI complicated lesions [2,3]. Conversely, intra-plaque b-GGT was inversely correlated with fibrosis and microcalcifications, commonly observed in stable plaques in either carotid or coronary arteries [10,12].

Several clinical and population studies have shown that serum GGT activity independently predicts the risk of acute cardiovascular events associated with atherosclerosis, including stroke [19-21,35,36]. However, the relationship between plaque GGT activity and histological features of plaque vulnerability has never been previously established. GGT is the main determinant of the extracellular glutathione hydrolysis [37] that causes the release of the dipeptide CysGly. The reactive thiol of CysGly may cause the reduction of ferric $\mathrm{Fe}(\mathrm{III})$ to ferrous iron $\mathrm{Fe}(\mathrm{II})$, starting a redoxcycling process with subsequent production of the reactive oxygen species superoxide anion and hydrogen peroxide [37]. These reactions could take place in the necrotic core of the plaque, where both GGT $[22,25,26]$ and iron are present at adequate concentrations [38]. In fact, in a previous study, we showed that in carotid 

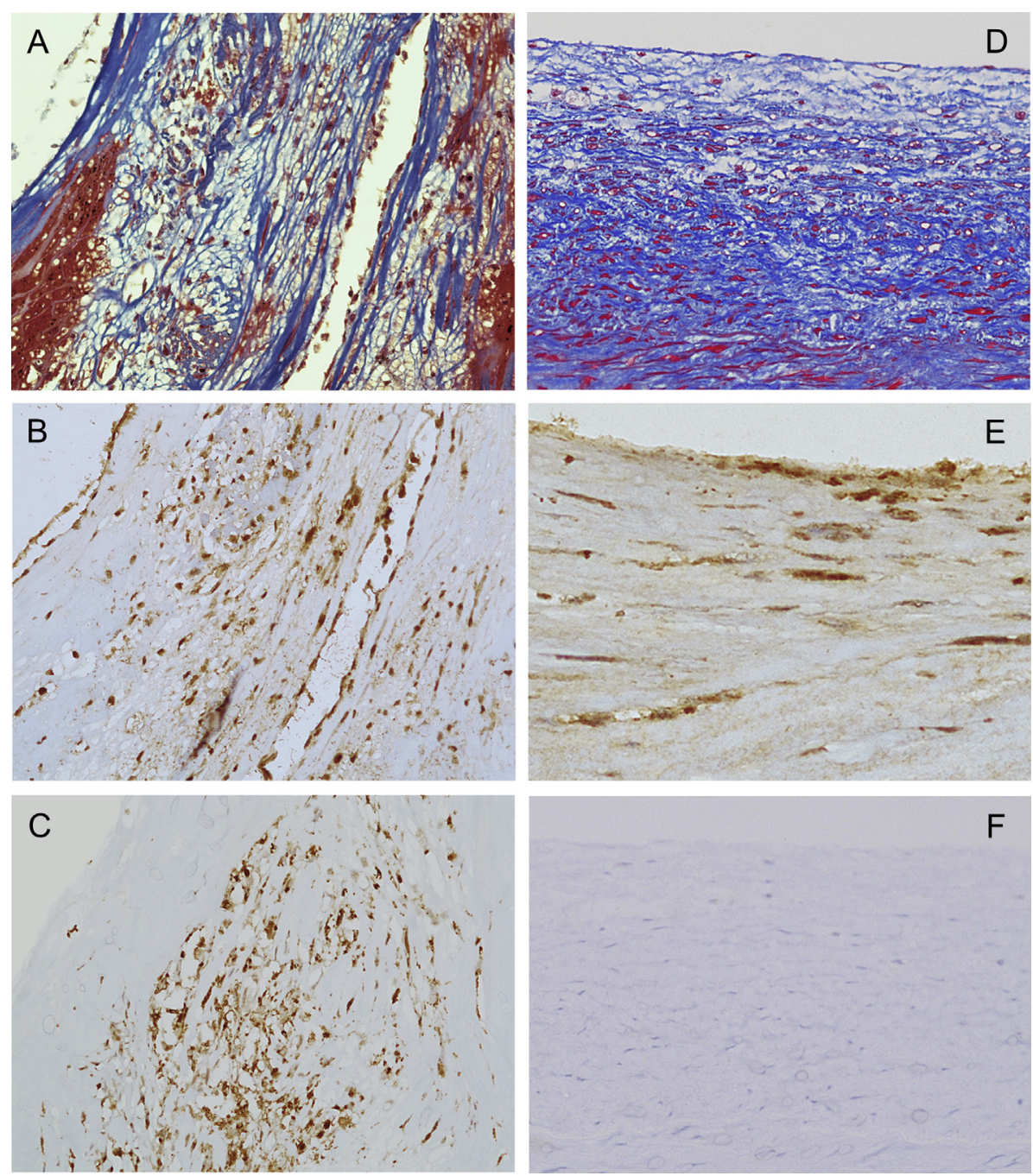

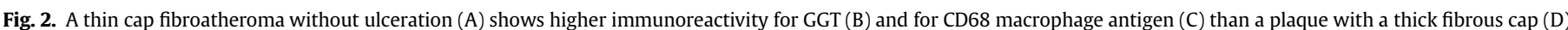

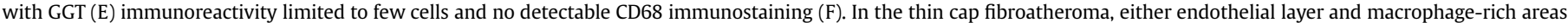

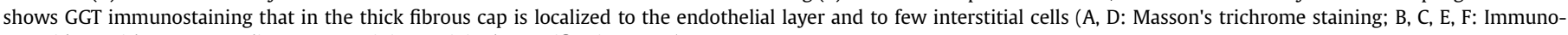
peroxidase with Haematoxylin counterstaining. Original magnification: $20 \times$ ).

plaques GGT activity coexists with products deriving from the prooxidant reactions catalysed by GGT, including protein-linked CysGly [26], the biochemical marker which documents that GGTmediated redox reactions have taken place $[26,39]$.

Redox events can play a relevant role in several processes favouring atherosclerotic plaque destabilization and rupture, i.e., LDL oxidation [23], activation of matrix metalloproteinase expression/activity and TIMP inhibition [25,40,41], matrix remodelling and fibrous cap thinning. Our study shows that intra-plaque b-GGT activity correlates with circulating b- and f-GGT level. This observation adds to findings from population studies showing the highest predictive value of serum total GGT activity for cardiovascular events at medium-high levels within normal 25-50 U/L reference range $[17,20,21]$. Metabolic and cardiovascular risk markers are important correlates of GGT fractions, in particular of b-GGT in healthy subjects [42] and in Framingham population [43]. It is noteworthy that non-alcoholic fatty liver disease, a component of the metabolic syndrome which is associated to increased cardiovascular risk [44], seems to be a rather specific cause of plasma b-GGT increase in blood [45], while alcohol abuse and liver diseases are more specifically associated with s-GGT elevation [46].
Interestingly we observed that fractional GGT analysis identified a unique distinct peak of b-GGT activity within plaque homogenates, thus raising the issue of the intra-plaque GGT-activity origin. The $2000 \mathrm{kDa}$ molecular weight of b-GGT corresponds to that of microparticles or exosomes and could allow its deposition within the plaque from the bloodstream through damaged endothelium in subjects with elevated plasma b-GGT level, while its ability to oxidize LDL [23] and its chemokine properties [47] could explain its co-localization with $\mathrm{CD} 68^{+}$macrophages. The association between intra-plaque b-GGT and $\mathrm{CD}^{+} 8^{+}$macrophage infiltration might even in part depend upon the ability of activated macrophages to release b-GGT, as already shown for neutrophils [48]. Furthermore, we observed a significant correlation between intra-plaque b-GGT and cholesterol plaque content. Either cholesterol increase and macrophage infiltration may lead to endothelial damage from oxidized-LDL, which might in turn facilitate plasma b-GGT passage into the plaque. Thus plaque GGT may derive both from insudation of plasma b-GGT as well as from endogenous synthesis by cellular elements of likely inflammatory nature. The major candidate are the macrophages that are known to express GGT activity [49] and that might be the source of the mRNA transcribed from GGT-I gene 

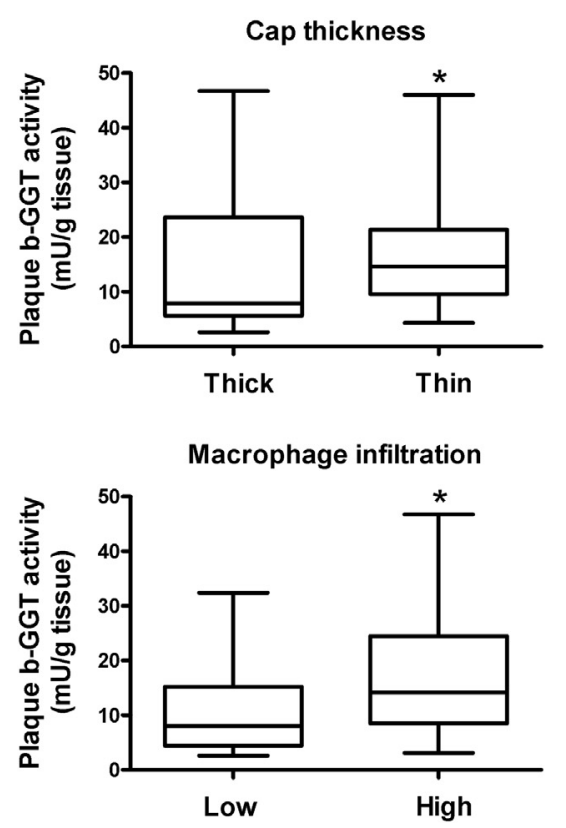

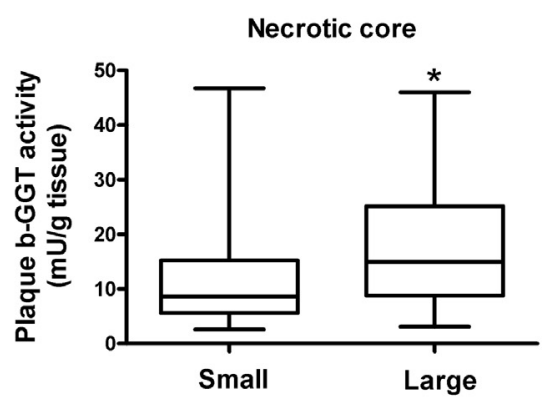

Fibrous Score

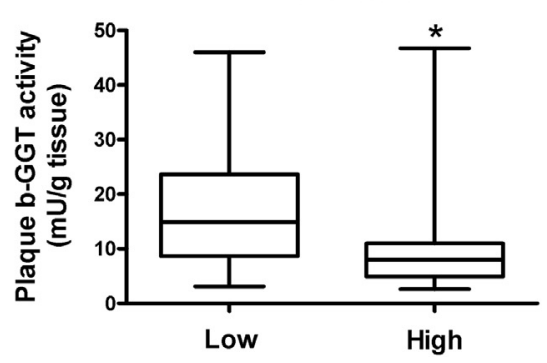

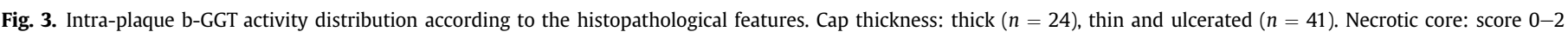

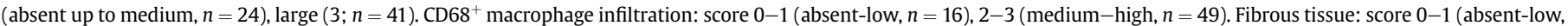
$n=47$ ), 2-3 (medium-high, $n=18$ ). Student's $t$ test has been performed on ln-transformed data. ${ }^{*} P<0.05$.

detectable in plaque homogenate [26]. Further studies will be aimed to elucidate how differentiation from monocytes, to macrophages and to foam cells influence GGT expression. The study of the properties of GGT expressed by macrophages will allow the quantification of the cellular and plasma contribution to intraplaque GGT activity.

Finally, the correlation between intra-plaque GGT activity and plasma f-GGT suggests that also this fraction might infiltrate into plaque through the damaged endothelium.

It is noteworthy that the intra-plaque residual GGT activity, even if greater then intra-plaque b-GGT activity, showed lesser association with histological features of plaque vulnerability, thus strengthening the role of b-GGT activity in plaque vulnerability.

In the present series including patients undergoing elective carotid endarterectomy, independently from presence of symptoms (observed only in a minority of patients, i.e., 15/65 subjects, $23 \%$ ) we did not observe any correlation between serum CRP levels and intra-plaque or circulating GGT levels; CRP is considered a nonspecific predictive marker of cardiovascular events and previous studies have shown that serum CRP and serum GGT are independent and additive predictors of cardiovascular events [17]. CRP and GGT might be related to different aspects of the atherosclerotic disease; elevated serum CRP levels appear more likely to indicate the systemic nature of progressive atherosclerotic disease rather than uncovering the presence of a single vulnerable lesion [50], whereas GGT could represent an index of on-going oxidative stress.

Limits of the study. This study did not investigate the possible relationships between b-GGT and symptomatic carotid artery disease; the selection criteria of this series (i.e., patients undergoing elective carotid endarterectomy on the basis of imaging results and of clinical evaluation) and the small number of patients with symptomatic disease $(N=15 / 65,23 \%)$ did not allow us to look for possible correlations between intra-plaque b-GGT activity, plaque histological features and cerebrovascular symptoms.

In conclusion, intra-plaque b-GGT was associated to histological features of vulnerable plaques in carotid endarterectomies, and to circulating b-GGT in the same patients. b-GGT fraction might play a role in atherosclerosis progression, and, rather than total GGT itself, might be related to the previously observed risk of acute cardiovascular events. On the basis of these results, future studies will be aimed to recruit a larger cohort for a prospective study in order to deepen the clinical meaning of circulating b-GGT in atherosclerotic disease; future applications for novel imaging monitoring of plaque instability might as well be evaluated.

\section{Sources of funding}

This work was supported by Institutional Funding.

\section{Disclosures}

None.

\section{Appendix A. Supplementary data}

Supplementary data related to this article can be found at http:// dx.doi.org/10.1016/j.atherosclerosis.2014.09.028.

\section{References}

[1] Lozano R, Naghavi M, Foreman K, Lim S, Shibuya K. Global and regiona mortality from 235 causes of death for 20 age groups in 1990 and 2010: a systematic analysis for the Global Burden of Disease Study 2010. Lancet 2012;380:2095-128.

[2] Stary HC, Chandler AB, Glagov S, Guyton JR, Insull Jr W, Rosenfeld MF Schaffer SA, Schwartz CJ, Wagner WD, Wissler RW. A definition of initial, fatty streak, and intermediate lesions of atherosclerosis: a report from the Committee on Vascular Lesions of the Council on Arteriosclerosis, American Heart Association. Special report. Arterioscler. Thromb. Vasc. Biol. 1994;14:840-56.

[3] Stary HC, Chandler AB, Dinsmore RE, Fuster V, Glagov S, Insull Jr W, Rosenfeld ME, Schwartz CJ, Wagner WD, Wissler RW. A definition of advanced types of atherosclerotic lesions and a histological classification of atherosclerosis. A report from the Committee on Vascular Lesions of the Council on Arteriosclerosis, American Heart Association. Circulation 1995;92:1355-74.

[4] Ross R. Atherosclerosis: an inflammatory disease. N. Engl. J. Med. 1999;340: 115-26.

[5] Shah Pk. Mechanisms of plaque vulnerability and rupture. J. Am. Coll. Cardiol 2003;41:15-22 
[6] Narula J, Nakano M, Virmani R, Kolodgie FD, Petersen R, Newcomb R, Malik S Fuster V, Finn AV. Histopathologic characteristics of atherosclerotic coronary disease and implications of the findings for the invasive and noninvasive detection of vulnerable plaques. J. Am. Coll. Cardiol. 2013;61:1041-51.

[7] Virmani R, Kolodgie FD, Burke AP, Farb A, Schwartz SM. Lessons from sudden coronary death: a comprehensive morphological classification scheme for atherosclerotic lesions. Arterioscler. Thromb. Vasc. Biol. 2000;20:1262-75.

[8] Redgrave JN, Lovett JK, Gallagher PJ, Rothwell PM. Histological assessment of 526 symptomatic carotid plaques in relation to the nature and timing of ischemic symptoms: the Oxford plaque study. Circulation 2006;113:2320-8.

[9] Mauriello A, Sangiorgi GM, Virmani R, Trimarchi S, Holmes Jr DR, Kolodgie FD, Piepgras DG, Piperno G, Liotti D, Narula J, Righini P, Ippoliti A, Spagnoli LG. A pathobiologic link between risk factors profile and morphological markers of carotid instability. Atherosclerosis 2010;208:572-80.

[10] Pucci A, Sheiban I, Formato L, Celeste A, Brscic E, Moretti C, De Bernardi A, Alberti A, Bergamasco L, Trevi G, Fuster V. In vivo coronary plaque histology in patients with stable and acute coronary syndromes: relationships with hyperlipidemic status and statin treatment. Atherosclerosis 2007;194: 189-95.

[11] Pucci A, Brscic E, Tessitore E, Celeste A, Crudelini M, De Bernardi A, Alberti A Biondi-Zoccai G, Sheiban I. C-reactive protein and coronary plaque composition in patients with percutaneous revascularization. Eur. J. Clin. Investig. 2008:38:281-9.

[12] Crisby M, Nordin-Fredriksson G, Shah PK, Yano J, Zhu J, Nilsson J. Pravastatin treatment increases collagen content and decreases lipid content, inflammation, metalloproteinases, and cell death in human carotid plaques; implications for plaque stabilization. Circulation 2001;103:926-33.

[13] Peeters W, Hellings WE, de Kleijn DP, de Vries JP, Moll FL, Vink A, Pasterkamp G. Carotid atherosclerotic plaques stabilize after stroke: insights into the natural process of atherosclerotic plaque stabilization. Arterioscler. Thromb. Vasc. Biol. 2009;29:128-33.

[14] Wilensky RL. In search of the elusive vulnerable plaque: reducing the gap between coronary imaging and necropsy findings. J. Am. Coll. Cardiol. 2013;61:1052-3.

[15] Hellings WE, Peeters W, Moll FL, Pasterkamp G. From vulnerable plaque to vulnerable patient: the search for biomarkers of plaque destabilization. Trends Cardiovasc. Med. 2007;17:162-71.

[16] Emdin M, Passino C, Donato L, Paolicchi A, Pompella A. Serum gammaglutamyltransferase as a risk factor of ischemic stroke might be independent of alcohol consumption. Stroke 2002;33:1163-4.

[17] Emdin M, Passino C, Michelassi C, Donato L, Pompella A, Paolicchi A. Additive prognostic value of gamma-glutamyltransferase in coronary artery disease. Int. J. Cardiol. 2009;136:80-5.

[18] Wilhelmsen L, Svardsudd K, Korsan-Bengtsen K, Larsson B, Welin L, Tibblin G. Fibrinogen as a risk factor for stroke and myocardial infarction. N. Engl. J. Med 1984;311:501-5.

[19] Jousilahti P, Rastenyte D, Tuomilehto J. Serum gamma-glutamyltransferase, self-reported alcohol drinking, and the risk of stroke. Stroke 2000:31:1851-5.

[20] Ruttmann E, Brant LJ, Concin H, Diem G, Rapp K, Ulmer H, Vorarlberg Health Monitoring and Promotion Program Study Group. Gamma-glutamyltransferase as a risk factor for cardiovascular disease mortality. An investigation in a cohort of 163,944 Austrian adults. Circulation 2005;112:2130-7.

[21] Emdin M, Passino C, Michelassi C, Titta F, L'abbate A, Donato L, Pompella A, Paolicchi A. Prognostic value of serum gamma-glutamyltransferase activity after myocardial infarction. Eur. Heart J. 2001;22:1802-7.

[22] Paolicchi A, Emdin M, Ghliozeni E, Ciancia E, Passino C, Popoff G, Pompella A. Human atherosclerotic plaques contain gamma-glutamyltranspeptidase enzyme activity. Circulation 2004;109:1440.

[23] Paolicchi A, Minotti G, Tonarelli P, Tongiani R, De Cesare D, Mezzetti A, Dominici S, Comporti M, Pompella A. Gamma-glutamyltranspeptidasedependent iron reduction and LDL oxidation - a potential mechanism in atherosclerosis. J. Investig. Med. 1999;47:151-60.

[24] Dominici S, Paolicchi A, Lorenzini E, Maellaro E, Comporti M, Pieri L, Minotti G Pompella A. Gamma-glutamyltransferase-dependent prooxidant reactions: a factor in multiple processes. Biofactors 2003;17:187-98.

[25] Emdin M, Pompella A, Paolicchi A. Gamma-glutamyltransferase, atherosclerosis, and cardiovascular disease: triggering oxidative stress within the plaque. Circulation 2005;112:2078-80.

[26] Franzini M, Corti A, Martinelli B, Del Corso A, Emdin M, Parenti GF, Glauber M, Pompella A, Paolicchi A. Gamma-glutamyltransferase activity in human atherosclerotic plaques-biochemical similarities with the circulating enzyme. Atherosclerosis 2009;202:119-27.

[27] Franzini M, Bramanti E, Ottaviano V, Ghiri E, Scatena F, Barsacchi R, Pompella A, Donato L, Emdin M, Paolicchi A. A high performance gel filtration chromatography method for gamma-glutamyltransferase fraction analysis. Anal. Biochem. 2008;374:1-6.

[28] Franzini M, Ottaviano V, Fierabracci V, Bramanti E, Zyw L, Barsacchi R, Scatena F, Boni C, Mammini C, Passino C, Pompella A, Emdin M, Paolicchi A. Fractions of plasma gamma-glutamyltransferase in healthy individuals: reference values. Clin. Chim. Acta 2008:395:188-9.
[29] Barnett HJ, Taylor DW, Eliasziw M, Fox AJ, Ferguson GG, Haynes RB, Rankin RN, Clagett GP, Hachinski VC, Sackett DL, Thorpe KE, Meldrum HE, Spence JD. Benefit of carotid endarterectomy in patients with symptomatic moderate or severe stenosis. North American Symptomatic Carotid Endarterectomy Trial Collaborators. N. Engl. J. Med. 1998;339:1415-25.

[30] North American Symptomatic Carotid Endarterectomy Trial Collaborators Beneficial effect of carotid endarterectomy in symptomatic patients with high-grade carotid stenosis. N. Engl. J. Med. 1991;325:445-53.

[31] MRC European Carotid Surgery Trial (ECST). Randomised trial of endarterectomy for recently symptomatic carotid stenosis: final results of the MRC European Carotid Surgery Trial (ECST). Lancet 1998;351:1379-87.

[32] Halliday A, Mansfield A, Marro J, Peto C, Peto R, Potter J, Thomas D, MRC Asymptomatic Carotid Surgery Trial (ACST) Collaborative Group. Prevention of disabling and fatal strokes by successful carotid endarterectomy in patients without recent neurological symptoms: randomised controlled trial. Lancet 2004:363:1491-502.

[33] Hanigan MH, Frierson Jr HF. Immunohistochemical detection of gammaglutamyltranspeptidase in normal human tissue. J. Histochem. Cytochem. 1996;44:1101-8.

[34] Rutenburg AM, Kim H, Fischbein JW, Hanker JS, Wasserkrug HL, Seligman AM. Histochemical and ultrastructural demonstration of gammaglutamyltranspeptidase activity. J. Histochem. Cytochem. 1969;17:517-26.

[35] Bots ML, Salonen IT, Elwood PC, Nikitin Y, Freire de Concalves A, Inzitari D, Sivenius J, Trichopoulou A, Tuomilehto J, Koudstaal PJ, Grobbee DE. Gammaglutamyltransferase and risk of stroke: the Eurostroke project. J. Epidemiol. Commun. Health 2002;56:25-9.

[36] Lee DS, Evans JC, Robins SJ, Wilson PW, Albano I, Fox CS, Wang TJ, Benjamin EJ, D'Agostino RB, Vasan RS. Gamma glutamyltransferase and metabolic syndrome, cardiovascular disease, and mortality risk: the Framingham Heart Study. Arterioscler. Thromb. Vasc. Biol. 2007:27:127-33.

[37] Whitfield JB. Gamma glutamyltransferase. Crit. Rev. Clin. Lab. Sci. 2001;38: $263-355$.

[38] Pang JH, Jiang MJ, Chen YL, Wang FW, Wang DL, Chu SH, Chau LY. Increased ferritin gene expression in atherosclerotic lesions. J. Clin. Investig. 1996;97: 2204-12.

[39] Corti A, Paolicchi A, Franzini M, Dominici S, Casini AF, Pompella A. The Sthiolating activity of membrane gamma-glutamyltransferase: formation of cysteinyl-glycine mixed disulfides with cellular proteins and in the cell microenvironment. Antioxid. Redox Signal. 2005;7(7-8):911-8.

[40] Libby P, Theroux P. Pathophysiology of coronary artery disease. Circulation 2005:111:3481-8.

[41] Galis ZS, Sukhova GK, Lark MW, Libby P. Increased expression of matrix metalloproteinases and matrix degrading activity in vulnerable regions of human atherosclerotic plaques. J. Clin. Investig. 1994;94:2493-503.

[42] Franzini M, Paolicchi A, Fornaciari I, Ottaviano V, Fierabracci V, Maltinti M, Ripoli A, Zyw L, Scatena F, Passino C, Pompella A, Emdin M. Cardiovascular risk factors and gamma-glutamyltransferase fractions in healthy individuals. Clin. Chem. Lab. Med. 2010:48:713-7.

[43] Franzini M, Fornaciari I, Rong J, Larson MG, Passino C, Emdin M, Paolicchi A, Vasan RS. Correlates and reference limits of plasma gammaglutamyltransferase fractions from the Framingham Heart Study. Clin. Chim. Acta 2013;417:19-25.

[44] Ahmed MH, Barakat S, Almobarak AO. Nonalcoholic fatty liver disease and cardiovascular disease: has the time come for cardiologists to be hepatologists? J. Obes, 2012:2012:483135.

[45] Franzini M, Fornaciari I, Fierabracci V, Elawadi HA, Bolognesi V, Maltinti S, Ricchiuti A, De Bortoli N, Marchi S, Pompella A, Passino C, Emdin M, Paolicchi A. Accuracy of b-GGT fraction for the diagnosis of non-alcoholic fatty liver disease. Liver Int. 2012;32:629-34.

[46] Franzini M, Fornaciari I, Vico T, Moncini M, Cellesi V, Meini M, Emdin M, Paolicchi A. High-sensitivity gamma-glutamyltransferase fraction pattern in alcohol addicts and abstainers. Drug Alcohol Depend. 2013;127:239-42.

[47] Niida S, Kawahara M, Ishizuka Y, Ikeda Y, Kondo T, Hibi T, Suzuki Y, Ikeda K, Taniguchi N. Gamma-glutamyltranspeptidase stimulates receptor activator of nuclear factor-kappaB ligand expression independent of its enzymatic activity and serves as a pathological bone-resorbing factor. J. Biol. Chem. 2004;279: 5752-6.

[48] Corti A, Franzini M, Cianchetti S, Bergamini G, Lorenzini E, Melotti P, Paolicchi A, Paggiaro P, Pompella A. Contribution by polymorphonucleate granulocytes to elevated gamma-glutamyltransferase in cystic fibrosis sputum. PLoS One 2012; 7:e34772.

[49] Schönfeld W, Schlüter B, Hilger R, König W. Leukotriene generation and metabolism in isolated human lung macrophages. Immunology 1988;65(4): 529-36

[50] Schillinger M, Exner M, Mlekusch W, Sabeti S, Amighi J, Nikowitsch R, Timmel E, Kickinger B, Minar C, Pones M, Lalouschek W, Rumpold $\mathrm{H}$, Maurer G, Wagner 0, Minar E. Inflammation and Carotid Artery-Risk for Atherosclerosis Study (ICARAS). Circulation 2005;111:2203-9. 